\title{
Monod Kinetics Degradation of Low Concentration Residual Organics in Membraneless Microbial Fuel Cells
}

\author{
A. Franzetti, ${ }^{a}$ M. Daghio, ${ }^{a}$ P. Parenti, ${ }^{a}$ T. Truppi, ${ }^{a}$ G. Bestetti, ${ }^{a}$ S. P. Trasatti, ${ }^{\text {b, }}$ \\ and P. Cristianic,z \\ ${ }^{a}$ Department DISAT, University of Milano, 20133, Milan, Italy \\ ${ }^{b}$ Department of Chemistry, University of Milano, 20133, Milan, Italy \\ ${ }^{c}$ Ricerca sul Sistema Energetico - RSE S.p.A., Environment and Sustainable Development Department, \\ 20134 Milan, Italy
}

\begin{abstract}
Microbial fuel cells (MFCs) are attracting considerable attention as innovative systems for energy production from renewable residua biomass and biomass-derived wastes dissolved in wastewaters. The current produced by a microbial fuel cell can also be used to quantify the rate of specific metabolic processes and the substrate concentration in real time. Aim of this work is the study of the correlation between the decay of current density in a microbial fuel cell and the concentration of the residual organic substrates when it reaches low concentration, in the rage of $0-500 \mathrm{mg} / \mathrm{L} \mathrm{COD}$. Tests were performed in continuous flow using an air breathing, membraneless MFC using sodium acetate as organic substrate. A direct concentration-dependent current output was achieved in the range of 0-100 mg/l, with a Monod kinetics as the best-fitting model. A step of current was also achieved at concentration higher than $120 \mathrm{mg} / \mathrm{L}$.

(C) The Author(s) 2016. Published by ECS. This is an open access article distributed under the terms of the Creative Commons Attribution 4.0 License (CC BY, http://creativecommons.org/licenses/by/4.0/), which permits unrestricted reuse of the work in any medium, provided the original work is properly cited. [DOI: 10.1149/2.0141703jes] All rights reserved.

(cc) BY
\end{abstract}

Manuscript submitted October 3, 2016; revised manuscript received November 30, 2016. Published December 30, 2016. This paper is part of the JES Focus Issue on Biological Fuel Cells.

Microbial fuel cells is a bioelectrochemical system that makes use of microorganisms or their enzymes to catalyse redox reactions on or near electrodes. Intensive studies of the possible applications of this technology are quite recent, although since more than 100 years they have been directed toward conversion of chemical energy into electrical energy. ${ }^{1}$ The process is based on the direct oxidation of organic carbon, or sulfides, biologically catalysed in anaerobic environments on the anode. ${ }^{2}$

The released electrons are transferred from the anode via an electrical circuit to a cathode where a reduction reaction takes place. This reduction can be chemically or biologically catalysed and a net energy gain is achieved. Recently, some studies tried to assess a correlation between the electrical output and the bioelectrochemical degradation of organic matter as a measure of the substrate concentration available for microbial degradation. The rationale behind this possible application is that electrical current is proportional to the electrons that flow into the electrochemical system per time unit. The electrical signal is therefore proportional to the extent at which the electrons are transferred to the electrode. The electron exchanged can thus be used as effective parameter to quantify the rate of specific metabolic processes in real time. ${ }^{3,4}$

Several studies already investigated the correlation between the current and the oxidation of specific organics and more complex organic matrix like wastewater. ${ }^{5,6}$ Mostly focalizing the attention on high electrical signal and high organic concentration, such as in the range of $500-3000 \mathrm{mg} / \mathrm{L} \mathrm{COD} .^{7}$ Other recent studies were focused on the signal trends variation due to biodegradation products from different organic matrices. ${ }^{8}$ Nevertheless, still few studies focused on the degradation kinetics in BES of relevant biodegradable organic chemicals frequently polluting waters ${ }^{9}$ and soils. ${ }^{10}$

Simple electrochemical biofilm sensor based on the current increase in a bio-battery made of Stainless Steel and Zinc, connected to an high value resistance and immersed directly in flow water ${ }^{11}$ or in soil, ${ }^{12}$ was successfully developed in the past, but with a different approach. Such devices are also based on the bacteria electroactivity, but on the Stainless Steel cathode that induce an increase of Zinc ions dissolution at the anode. They were mostly addressed to monitor the presence of biofilm and toxics (oxidants in particular) able to destroy

\footnotetext{
*Electrochemical Society Fellow.

${ }^{\mathrm{z}}$ E-mail: pierangela.cristiani@rse-web.it
}

or inhibit the bacteria metabolism, as opposed to targeting to monitor the nutrients inducing bacteria growth. An exception is a biofilm sensor applied in soils enriched with organic recalcitrant, ${ }^{12}$ although in that case the target was the electrochemical on-line monitoring of the bacteria activity in the soil and not the kinetic of the biodegradation process.

The present experimentation addresses the new target of developing a simple bioelectrochemical sensor of the residual biodegradable organics dissolved in the water, using a microbial fuel cell. The concentration of few $\mathrm{mg} / \mathrm{L}$ of chemical oxygen demand (COD) is under investigation, the most frequent in natural water bodies. ${ }^{13} \mathrm{~A}$ special attention has been paid to the concentration range of $0-120 \mathrm{mg} / \mathrm{L} \mathrm{COD}$, which is the maximum COD allowed at the discharge of the wastewater plants by the Italian rule ${ }^{14}$ and European recommendations (UE Water Framework Directive).

\section{Materials and Methods}

Experimentation.-For this experimentation, three identical single Chamber and mediatorless MFCs, with both electrodes made of carbon cloth, were operated in flow condition (Figure 1) and in batch mode. Sodium acetate were investigated as biodegradable organic fuel, using the wastewater coming from a treatment plant in Milan as media and inoculum.
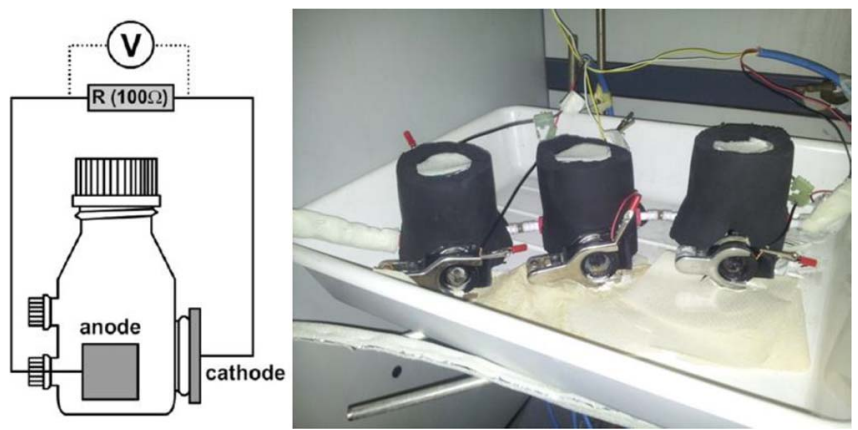

Figure 1. Scheme of an air breathing MFC and picture of the MFC set used in sequence of flow. 
Sodium acetate was added as sole carbon source into the bottle, at two different concentrations: i) $3 \mathrm{~g} / \mathrm{L}$ for a single batch cycle, to preliminary boost the biofilm growth on the electrodes and to assess the maximum output from the MFCs; ii) $300 \mathrm{mg} / \mathrm{L}$ repeated more batch cycles, to explore how the MFCs perform at the range of common pollution of water bodies.

Residual concentration of acetate during each batch cycle was estimated by periodic COD analyses. The MFCs were operated with an external load $\mathrm{R}$ of $100 \Omega$. The electric current generated in the MFCs was monitored and registered every fifteen minutes over time. Temperature, $\mathrm{pH}$ and redox potential was also periodically measured during the trials. At the end of the experimentation, anodic and cathodic biofilm samples were aseptically collected and the bacteria communities were analyzed by $16 \mathrm{~S}$ rRNA gene sequencing.

MFC set up.-Three single chamber MFCs (solution volume: 125 $\mathrm{mL}$ ) was hydraulically connected with tubes of Tygon and operated in continuous flow, connected in line as shown in Figure 1. A threeway tap was inserted between each hydraulic connection for sampling. The MFCs were filled with raw wastewater sampled from a wastewater treatment plant in Milan. A bottle of $5 \mathrm{~L}$ was used as solution reservoir of the solution re-circulating through the three MFCs. A flow water of $1.8 \mathrm{~L} / \mathrm{h}$ was set using a peristaltic pump (SP 311, Velp Scientific). The reservoir bottle was thermostated at temperature of $29 \pm 2{ }^{\circ} \mathrm{C}$. The MFCs and the hydraulic line were enveloped with a polyethylene roll, to prevent light irradiation and thermostated.

Electrodes.-A piece of $5 \times 2 \mathrm{~cm}$ of carbon cloth (SEAL, Legnano, Italy) was used as anode. One side of the anode (Figure 1) was electrically connected with the tip of an electric copper wire imbibed in a conductive paint (Timcal Li-quid 101). The carbon cloth-copper connection was then covered with an insulating coating of two-component resin (Epojet Mapei).

The cathode was set with the same carbon cloth but enriched with carbon powder spread using a facile technique, although not optimized, avoiding any pressure/heat-treatment and any additional chemical catalyst. A carbon Micro-Porous Layer (MPL) of 30-50 $\mu \mathrm{m}$ containing Nafion 30\% (w/w) dissolved in isopropanol alcohol was pressed with a spatula on the external face of the carbon cloth and dried at air, since it was found to enhance oxygen exchange and facilitate the biofilm growth. ${ }^{7,15}$ The other side of the carbon cloth, exposed to the air, was enriched with another layer of cold spread carbon powder mixed with PTFE $60 \%$ (w/w). Previous works ${ }^{16}$ demonstrated this PTFE percentage is effective in limiting water leakages without inhibiting the cathodic process of oxygen discharge as higher PTFE content do.

Optimized cathode with lower PTFE needs thermal treatment to make the cathode performing at best. ${ }^{17}$ This simplified procedure was selected as the purpose of the work is to study a system generating low current, because the low concentration of fuel, expected to be in the range of few hundred of $\mathrm{mAm}^{-2}$.

Chemical oxygen demand (COD) analysis.-COD was measured with colorimetric kit (Hach Lange: LCK 014, LCK 314, LCK 414 e LCK 514). Wastewater sampled outlet the three MFCs was first centrifuged (Rotofix $32^{\circ}$, Hettich Zentrifugen) for 15 minutes at 6000 $\mathrm{RPM}$, then heated for 15 minutes at $170^{\circ} \mathrm{C}$ (heater Hach Lange HT200 S). The principle of the method is based on the strong oxidant $\mathrm{Cr}_{2} \mathrm{O}_{7}^{2-}$ ion in acidic condition.

Chemical-physical measurements.-Temperature, redox potential, conductivity and $\mathrm{pH}$ were measured with Delta Ohm devices (respectively: Voltmeter HD $2105.2 \mathrm{vs} \mathrm{Ag} / \mathrm{AgCl}$ (3 M) reference; conductimeter HD 2106.2; pHmeter HD 2105.2, with the glass electrode InLab Solid ( $\left.\mathrm{pH} 1-11,0-80^{\circ} \mathrm{C}\right)$ equipped with temperature probe (TP47.1000 Pt1000 2 wires).

Amplification of the 16S rRNA gene, sequencing and sequence analyses.-Total bacterial DNA was extracted using the FastDNA

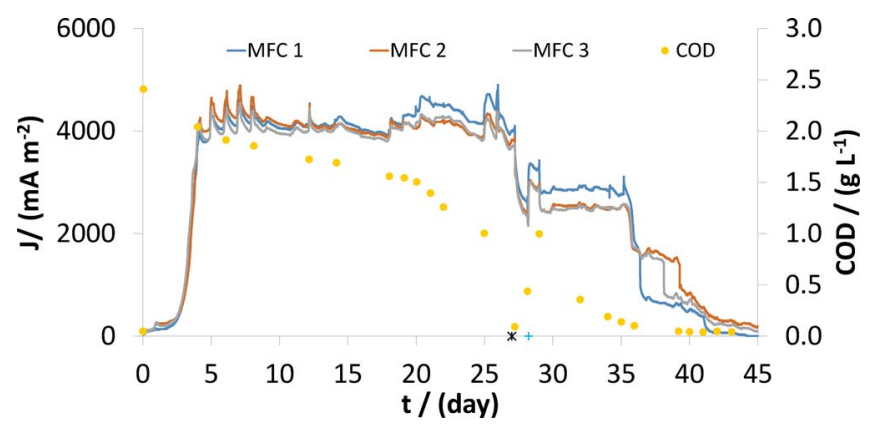

Figure 2. Trend of MFC current density produced during the preliminary acclimation with high initial dosage of $3 \mathrm{~g} / \mathrm{L}$ sodium acetate and COD measured in time; ${ }^{*}$ indicates acetate spiking.

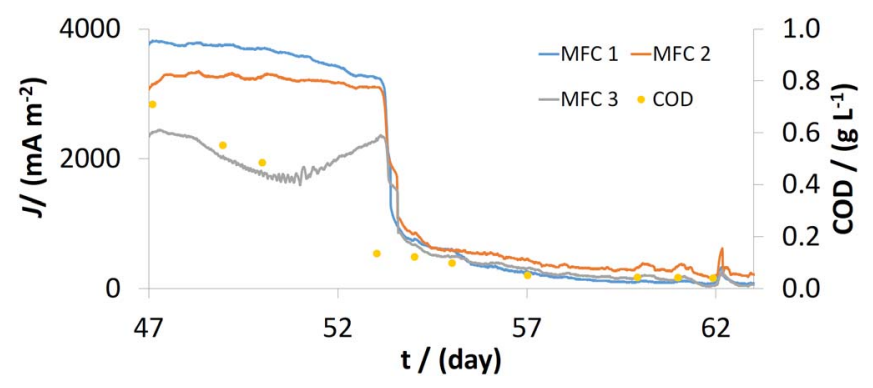

Figure 3. Trend of MFC current density and COD after a dosage of $1 \mathrm{~g} / \mathrm{L}$ of acetate (experiment 1$)$.

Spin for Soil kit (MP Biomedicals, Solon, OH, USA) according to the manufacturer's instructions. Amplification of the V5-V6 hypervariable regions of the $16 \mathrm{~S}$ rRNA gene was carried out as previously described. ${ }^{18}$ The sequencing was carried out at the Parco Tecnologico Padano (Lodi, Italy). Forward and reverse reads were merged with perfect overlapping and quality filtered with default parameters using Uparse pipeline. ${ }^{19}$ Sequences were taxonomically classified by RDP classifier ( $>80 \%$ confidence) ${ }^{20} \mathrm{~A}$ hierarchical cluster analysis based on Hellinger transformed Operational Taxonomic Unit (OTU) relative abundance data was performed with the HCLUST procedure in R 3.0.2. ${ }^{21}$

\section{Results and Discussion}

The Figure 2 shows the trend of current density $(j)$ generated in MFC during bacteria acclimation induced with an high dosage of 3 $\mathrm{g} / \mathrm{L}$ sodium acetate, and its decay up to the total consumption of COD concentration. The current similarly decreased in the three MFCs as consequence of the acetate consumption after: i) the subsequent dosage of $1 \mathrm{~g} / \mathrm{l}$ acetate (Figure 3); ii) other dosages of $300 \mathrm{mg} / \mathrm{L}$, in subsequent feeding cycles, during 100 days test (Figure 4).

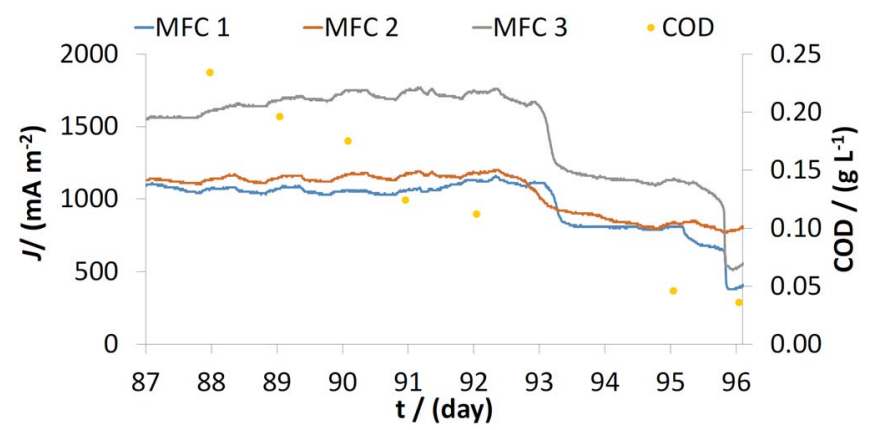

Figure 4. Trend of MFC current density and COD after a dosage of $300 \mathrm{mg} / \mathrm{L}$ acetate (experiment 2). 

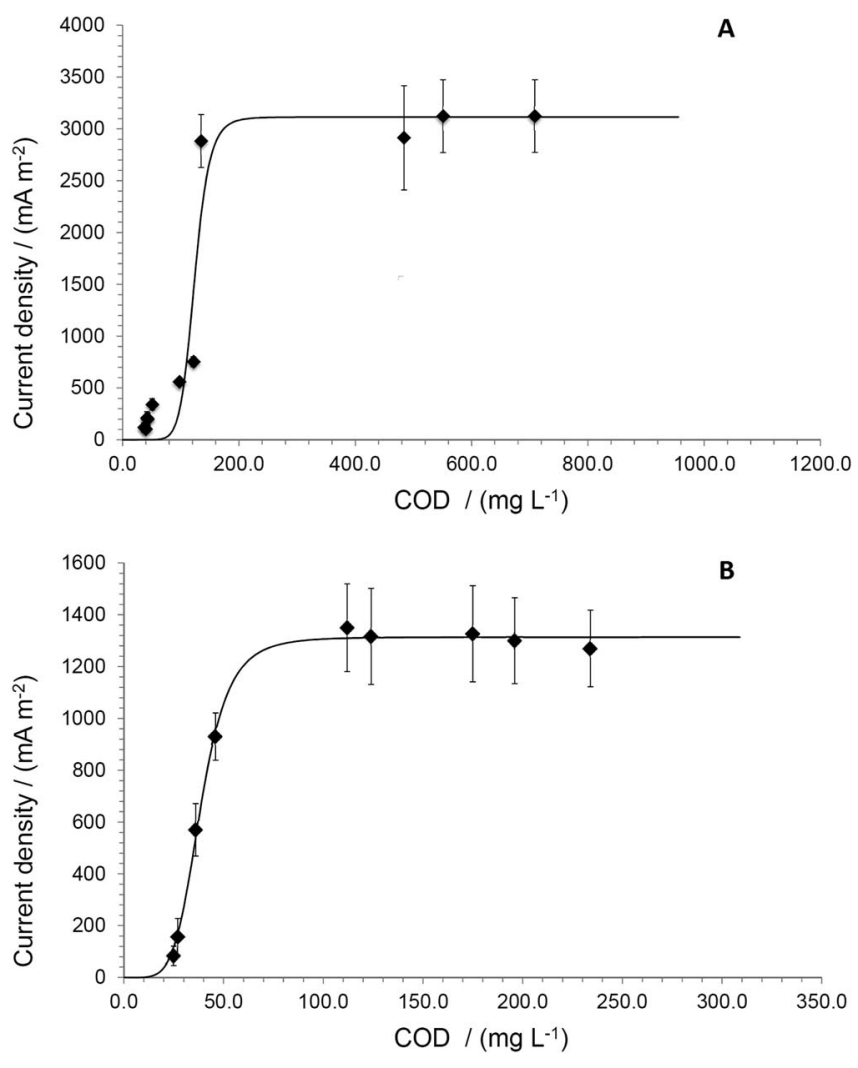

Figure 5. Graphic and data fitting with modified Monod model of current vs COD in experiment 1 ( $\mathrm{A}, 1 \mathrm{~g} / \mathrm{L}$ COD dosage) and in experiment 2 (B, $300 \mathrm{mg} / \mathrm{L}$ COD dosage).

Figure 5 shows the relationship between the punctual values of current density and the corresponding COD values measured in the experiment with a dosage of $1 \mathrm{~g} / \mathrm{L}$ of acetate (experiment 1 , panel A) and $300 \mathrm{mg} / \mathrm{L}$ of acetate (experiment 2, panel B).

Substrate removal is most commonly modelled with a Monod or a linear rate equation. Data has been fitted with different kinetics models and showed the best fitting $\left(\mathrm{R}^{2}=0.997\right)$ with a modified Monod model (Equation 1) which parameters are defined in the Nomenclature list.

$$
\mu=\mu \operatorname{MAX} \frac{[S]^{n}}{K_{S}+[S]^{n}}
$$

Data from the experiment with a dosage of $300 \mathrm{mg} / \mathrm{L} \mathrm{COD} \mathrm{showed}$ a better fitting with the modified Monod than those from the experiment 1 (dosage $1 \mathrm{~g} / \mathrm{L}$ COD). Best fitting parameters of the models, which is applied considering a single substrate (acetate) system, were: $\mathrm{Ks}=38.5 ; \mu_{\max }=1313 ; \mathrm{n}=5.93 ; \mathrm{R}^{2}=0.997$ for experiment $1 ; \mathrm{Ks}$ $=38.5 ; \mu_{\max }=1313 ; \mathrm{n}=5.93 ; \mathrm{R}^{2}=0.997$ for experiment 2 .

Result from both experiments indicated that, after the acclimation in the tested condition, the MFCs are able to return a stable current output of about $300 \mathrm{~mA} / \mathrm{m}^{2}$ for concentration in the range of $200-1000 \mathrm{mg} / \mathrm{L}$ COD which decreased linearly down to $0 \mathrm{~mA} / \mathrm{m}^{2}$ in the range of concentration between 0 and $100 \mathrm{mg} / \mathrm{L}$ COD. These results are consistent with those previously reported in the literature for MFC-based BOD both in term of detection rate and current output. ${ }^{22}$

Considering the COD values in the range of $0-120 \mathrm{mg} / \mathrm{L}$ in both experiments, the linear relationships between COD and current output was estimated and reported in Figure 6.

Although in the same range of substrate concentration, the slope of the fitting lines significantly differed between the two experiments.

Particularly, the biosensor during the experiment 2 had higher sensitivity to increasing substrate concentration. This contrast with a previous report of a MFC biosensor, where the repeatability of

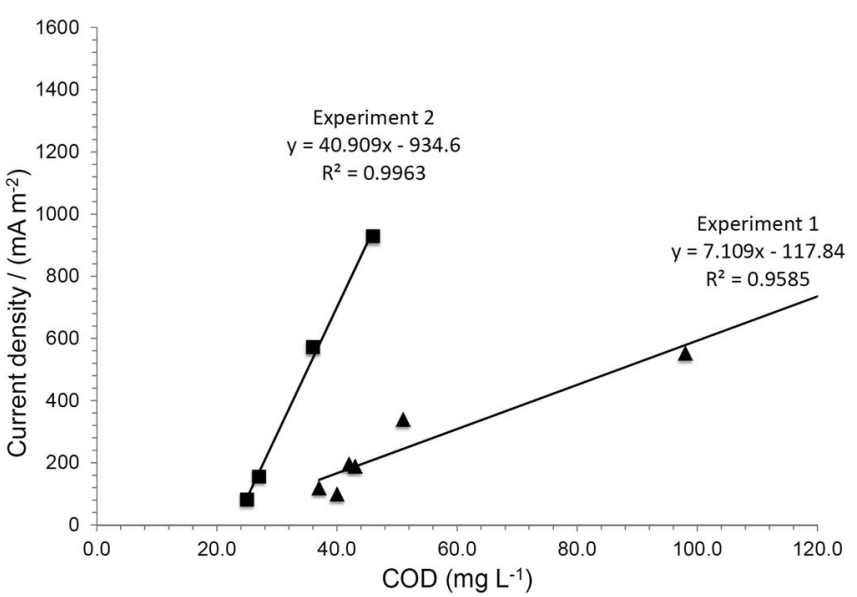

Figure 6. Linear relationship between current density and COD at low COD values $(0-120 \mathrm{mg} / \mathrm{L})$ for both experiments.

current output at $100 \mathrm{mg} / \mathrm{L}$ BOD was less than $10 \%$ after different feeding cycle. ${ }^{23}$ However, it is worth reporting that current density and sensitivity of the biosensor in experiment 2 resulted generally higher than those previously reported in literature. ${ }^{24}$

Sensitivity changes over time indicates that at fixed biosensor configuration the biofilm dynamics and maturation might play a crucial role in determining the sensitivity of the sensor.

Unfortunately, bacterial community structure of biofilm from experiments 1 is not available in this study. However, we demonstrated that community structure of electrode biofilm that has not been fed for two months significantly differed from that sampled during biosensor feeding (see next paragraph).

Characterization of the microbial communities.-At the end of three months of experimentation, the electrodes of one of the operating MFCs was sampled for microbiological analyses (A6_yes and C6_yes for anode and cathode, respectively), while the other two MFCs were left without feeding for one month before the electrode sampling (A4_No/A5_No and C4_No/C5_No for anode and cathode, respectively).

In this way operating and not more operating anodes and cathodes were sampled for the amplification and sequencing of the 16S rRNA gene. Figures 7 and 8 reports the main microbiological families detected by sequencing analysis on the sampled air breathing cathodes and anodes.

A hierarchical cluster analysis on Hellinger transformed OTU relative abundance data is reported in Figure 9. It is clearly showed a difference between the non-working anodes (A4_No and A5_No) and the working anode (A6_Yes).

The presence of the families Geobacteraceae and Porphyromonadaceae (genus Proteiniphilum) was observed both on the anode (respectively $1 \%$ and $2 \%$ ) and on the cathode (respectively $5 \%$ and $3 \%$ ) of the working MFC, while their presence was negligible in the samples collected from the non-working MFCs (Figure 7 and Figure 8). Similarly, members of the families Desulfobulbaceae (3\%), Nocardiaceae (12\%) and Parachlamydiaceae (8\%) were enriched on the working anode.

The family Comamonadaceae was the most abundant group on the non-working anodes (between $25 \%$ and $31 \%$ ). The family Rhodocyclaceae was enriched on the cathodes (between $10 \%$ and $11 \%$ ) but only a low amount of these microorganisms were selected on the anodes (about 1\%).

Several microbial groups may be linked to current production in the tested MFCs. Microorganisms of the families Geobacteraceae and Porphyromonadaceae were enriched both on the cathode and on the anode of the working cell. The presence of the anaerobic 


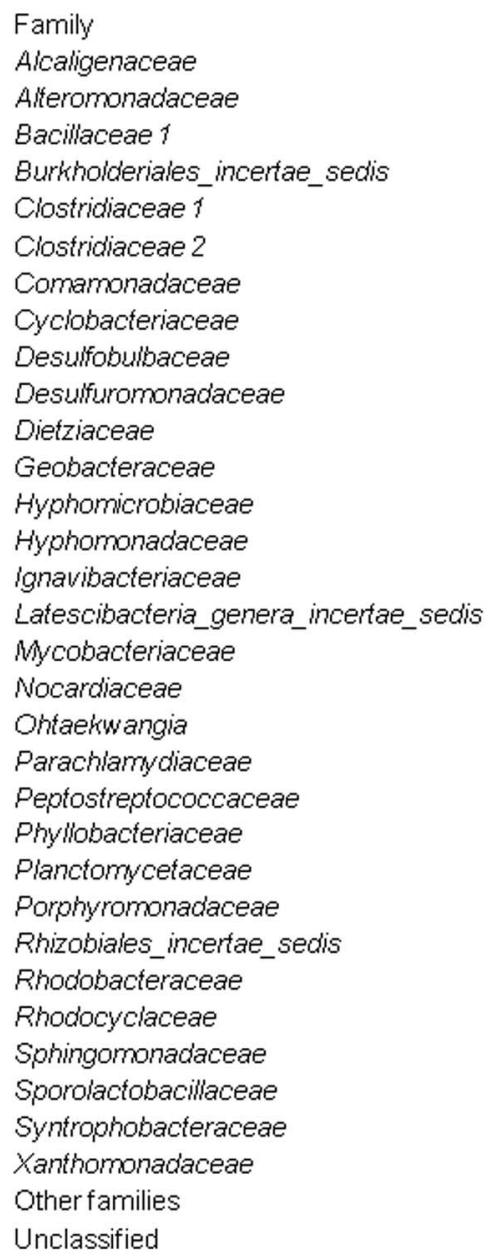

\begin{tabular}{|c|c|c|c|c|c}
\hline MFC1_A & MFC2_A & MFC3_A & MFC1_C & MFC2_C MFC3_C \\
\hline $0 \%$ & $0 \%$ & $2 \%$ & $0 \%$ & $0 \%$ & $1 \%$ \\
\hline $0 \%$ & $0 \%$ & $0 \%$ & $2 \%$ & $0 \%$ & $1 \%$ \\
\hline $1 \%$ & $1 \%$ & $3 \%$ & $1 \%$ & $1 \%$ & $0 \%$ \\
\hline $4 \%$ & $2 \%$ & $0 \%$ & $1 \%$ & $1 \%$ & $0 \%$ \\
\hline $2 \%$ & $4 \%$ & $0 \%$ & $0 \%$ & $1 \%$ & $0 \%$ \\
\hline $0 \%$ & $0 \%$ & $1 \%$ & $4 \%$ & $0 \%$ & $0 \%$ \\
\hline $25 \%$ & $31 \%$ & $6 \%$ & $2 \%$ & $8 \%$ & $2 \%$ \\
\hline $0 \%$ & $0 \%$ & $2 \%$ & $12 \%$ & $5 \%$ & $3 \%$ \\
\hline $0 \%$ & $0 \%$ & $3 \%$ & $0 \%$ & $0 \%$ & $0 \%$ \\
\hline $0 \%$ & $0 \%$ & $0 \%$ & $0 \%$ & $0 \%$ & $2 \%$ \\
\hline $0 \%$ & $0 \%$ & $0 \%$ & $1 \%$ & $0 \%$ & $2 \%$ \\
\hline $0 \%$ & $0 \%$ & $1 \%$ & $0 \%$ & $0 \%$ & $5 \%$ \\
\hline $0 \%$ & $0 \%$ & $0 \%$ & $0 \%$ & $1 \%$ & $0 \%$ \\
\hline $4 \%$ & $4 \%$ & $3 \%$ & $1 \%$ & $5 \%$ & $1 \%$ \\
\hline $0 \%$ & $0 \%$ & $3 \%$ & $0 \%$ & $0 \%$ & $0 \%$ \\
\hline $1 \%$ & $0 \%$ & $0 \%$ & $0 \%$ & $0 \%$ & $0 \%$ \\
\hline $3 \%$ & $3 \%$ & $4 \%$ & $1 \%$ & $2 \%$ & $0 \%$ \\
\hline $5 \%$ & $4 \%$ & $12 \%$ & $0 \%$ & $2 \%$ & $0 \%$ \\
\hline $0 \%$ & $1 \%$ & $0 \%$ & $0 \%$ & $1 \%$ & $0 \%$ \\
\hline $0 \%$ & $0 \%$ & $8 \%$ & $1 \%$ & $0 \%$ & $0 \%$ \\
\hline $1 \%$ & $1 \%$ & $3 \%$ & $0 \%$ & $0 \%$ & $0 \%$ \\
\hline $0 \%$ & $0 \%$ & $3 \%$ & $1 \%$ & $0 \%$ & $0 \%$ \\
\hline $2 \%$ & $1 \%$ & $2 \%$ & $2 \%$ & $4 \%$ & $0 \%$ \\
\hline $0 \%$ & $0 \%$ & $2 \%$ & $0 \%$ & $0 \%$ & $3 \%$ \\
\hline $3 \%$ & $2 \%$ & $1 \%$ & $2 \%$ & $2 \%$ & $0 \%$ \\
\hline $4 \%$ & $5 \%$ & $1 \%$ & $7 \%$ & $21 \%$ & $3 \%$ \\
\hline $1 \%$ & $1 \%$ & $1 \%$ & $10 \%$ & $11 \%$ & $10 \%$ \\
\hline $6 \%$ & $5 \%$ & $5 \%$ & $0 \%$ & $4 \%$ & $0 \%$ \\
\hline $0 \%$ & $0 \%$ & $0 \%$ & $1 \%$ & $0 \%$ & $2 \%$ \\
\hline $0 \%$ & $0 \%$ & $1 \%$ & $0 \%$ & $0 \%$ & $0 \%$ \\
\hline $11 \%$ & $12 \%$ & $3 \%$ & $15 \%$ & $12 \%$ & $29 \%$ \\
\hline $3 \%$ & $3 \%$ & $5 \%$ & $4 \%$ & $2 \%$ & $5 \%$ \\
\hline $21 \%$ & $19 \%$ & $23 \%$ & $30 \%$ & $15 \%$ & $28 \%$ \\
\hline & & & & & \\
\hline
\end{tabular}

Figure 7. Taxonomic composition at family level of the microbial communities enriched on the anodes (non-working anodes - A4_No and A5_No - and working anode - A6_Yes) and on the cathodes (non-working cathodes - C4_No and C5_No - and working cathode - C6_Yes). The families with a relative abundance of $1 \%$ (or higher) are reported.

microorganisms at the anode is expected due to the use of the electrode as terminal electron acceptors in absence of oxygen. Conversely, at the cathode both aerobic and anaerobic bacteria are expected to colonize an air exposed cathode. The biofilm on the cathode enhances the cathodic reaction and sustains anaerobiosis in membraneless MFCs. Indeed, a thin aerobic biofilm layer close to the air interphase consume incoming oxygen and avoids its diffusion into the cell. This phenomenon favors the growth of anaerobic biofilm on the cathode water side, which thickness can reach quickly, in few weeks, the size of $0.5 \mathrm{~mm}^{25}$ The consortium of aerobic ${ }^{11}$ and anaerobic bacteria can synergistically sustain the cathodic reaction, transferring electron to the oxygen in several ways, as discussed in previous works. ${ }^{7,26}$

Members of the family Geobacteraceae belonging to the genus Geobacter have been extensively described for their ability to use electrodes as sole electron acceptors ${ }^{27}$ or donors. ${ }^{28}$ Similarly, the presence of the family Porphyromonadaceae was described on the anode of continuous flow MFC fed with synthetic wastewater and pig slurry, ${ }^{29}$ and on the cathode of a single chamber MFC inoculated with biogas digestate. ${ }^{30}$ Microorganisms linked to sulfur cycle seemed to play a role in the working reactor as previously observed in other studies. ${ }^{26,31,32}$

Members of the Desulfobulbaceae are the so called cable bacteria, which are able to transfer the electrons derived from the oxidation of sulfide over centimeter distances in marine sediments. ${ }^{33}$ The importance of the family Desulfobulbaceae during the bioelectrochemical removal of aromatic hydrocarbons has been hypothesized both in dou- ble chamber reactors with polarized anodes (i.e. $0 \mathrm{mV}$ and $+300 \mathrm{mV}$ vs $\mathrm{Ag} / \mathrm{AgCl})^{31}$ and in single chamber reactors, ${ }^{32}$ by linking the oxidation of sulfide, produced by sulfate reduction, to electrons transfer to the anode.

The family Rhodocyclaceae was enriched on the cathodes and in lower amount on the anodes of both the working reactors and non-working reactors. The presence of microorganisms of the family Rhodocyclaceae was observed on the anode of a microbial fuel cell and in the control reactor (which failed to produce current) during benzene degradation. ${ }^{34}$ In the same study members of the Rhodocyclaceae were enriched on the cathodes. The authors however hypothesized that their presence was linked to the degradation of residual benzene from the anode. $^{34}$

The cluster analyses reported in Figure 9 underlines the statistically significant difference between working and not more working electrodes, other than anodes and cathodes.

The results of the present work suggest that the analysis of the microbial community can also gave insight on operating conditions of the cells in an integrated period of time. Indeed, nutrient, substrate availability and the presence of toxic compounds should differently affect the structure of the microbial communities in the biosensor. Analyzing the microbial community might contribute to understand the cause of the electrical signal decay.

Furthermore, although acetate is the most common fermentation by-product, the presence of compounds produced by different fermentative pathways (e.g. lactate, butyrate) might select different microbial populations on biosensor electrodes. 


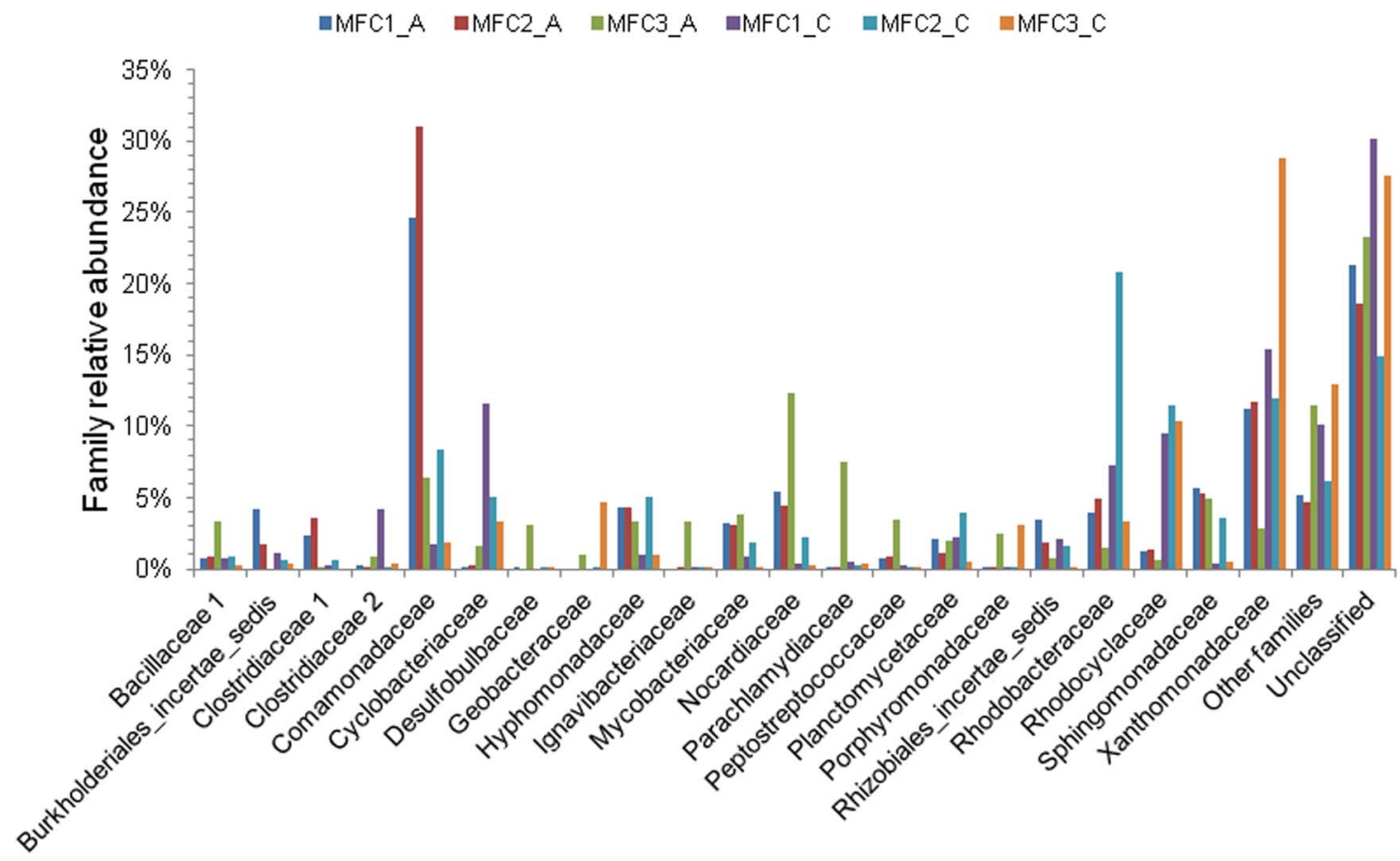

Figure 8. Taxonomic composition at family level of the microbial communities enriched on the anodes (non-working anodes - A4_No and A5_No - and working anode - A6 Yes) and on the cathodes (non-working cathodes - C4 No and C5 No - and working cathode - C6 Yes). The families with a relative abundance of $3 \%$ (or higher) are reported.

Based on the achieved results, therefore, future works will investigate whether different organic nutrients affect the performance and the nature of the electroative bacterial populations, and their evolution in time.

\section{Conclusions}

The possibility to apply air breathing MFCs operated in flow condition for the monitoring of organic nutrient trend in natural waters was investigated.

The results indicate a linear correlation of current density generated in MFCs and the COD concentration of $0-120 \mathrm{mg} / \mathrm{L}$, the maximum allowed at the discharge of industrial sites by European laws. This result indicates the possibility for usage of current trend generated in MFCs as early warning signal of possible water pollution.

Although in literature stable and reproducible current outputs have been achieved, the present results showed that the community structure of electrode biofilm depends on feeding regime of the MFC which in turn might affect the stability of the biosensor sensitivity over time.

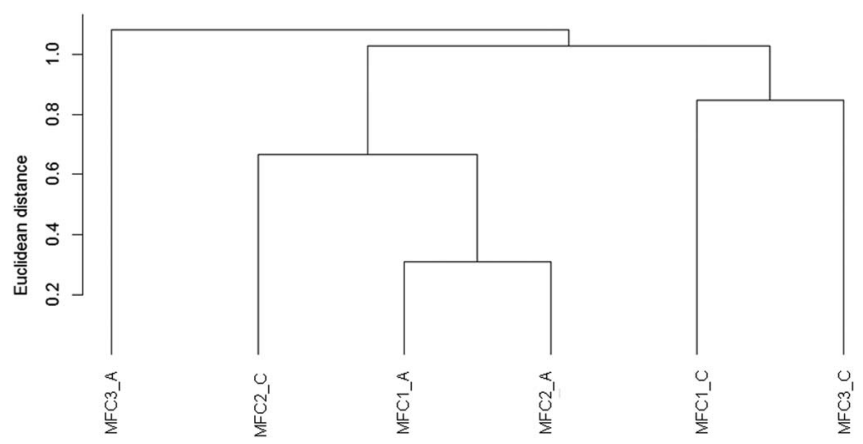

Figure 9. Hierarchical cluster analysis performed on Hellinger transformed OTU relative abundance data. Non-working anodes (A4_No and A5_No) were grouped in a different cluster compared to and working anode (A6_Yes).

\section{Acknowledgments}

This work was financed by the Research Fund for the Italian Electrical System under the Contract Agreement between RSE and the Ministry of Economic Development - General Directorate for Nuclear Energy, Renewable Energy and Energy Efficiency (July 29, 2009March 19, 2009).

\section{List of Symbols}

$\mu \quad$ specific growth rate of microorganisms

$\mu_{\max } \quad$ maximum specific growth rate of microorganisms

$\mathrm{S} \quad$ substrate concentration $(\mathrm{mg} / \mathrm{L})$

Ks $\quad$ half-saturation coefficient $=\mathrm{S}$ when $\mu / \mu_{\max }$ is 0.5

$n \quad$ intrinsic kinetic coefficient (empirical parameter).

\section{References}

1. J. B. a Arends and W. Verstraete, Microb. Biotechnol., 5, 333 (2012).

2. K. Rabaey, K. Van de Soempel, L. Maignien, N. Boon, P. Aelterman, P. Clauwaert, L. De Schamphelaire, H. T. Pham, J. Vermeulen, M. Verhaege, P. Lens, and W. Verstraete, Environ. Sci. Technol., 40(17), 5218 (2006).

3. A. Prévoteau, A. Geirnaert, J. B. A. Arends, S. Lannebère, T. Van de Wiele, and K. Rabaey, Sci. Rep., 5, 11484 (2015)

4. A. Kumlanghan, J. Liu, P. Thavarungkul, P. Kanatharana, and B. Mattiasson, Biosens. Bioelectron., 22(12), 2939 (2007).

5. J. M. Tront, J. D. Fortner, M. Plötze, J. B. Hughes, and a M. Puzrin, Biotechnol. Lett., 30(8), 1385 (2008).

6. B. H. Kim, I. S. Chang, G. C. Gil, H. S. Park, and H. J. Kim, Biotechnol. Lett., 25, 541(2003).

7. P. Cristiani, M. L. Carvalho, E. Guerrini, M. Daghio, C. Santoro, and B. Li, Bioelectrochemistry, 92, 6 (2013).

8. P. C. Colombo Alessandra, Andrea Schievano, Stefano P. Trasatti, Raffaele Morrone and Nicola D'Antona, International Journal of Hydrogen Energy, (2016).

9. J. Rakoczy, S. Feisthauer, K. Wasmund, P. Bombach, T. R. Neu, C. Vogt, and H. H. Richnow, Biotechnol. Bioeng., 110(12), 3104 (2013).

10. L. Lu, T. Huggins, S. Jin, Y. Zuo, and Z. J. Ren, Environ. Sci. Technol., 48(7), 4021 (2014).

11. P. Cristiani, Applied Thermal Engineering, 25(16), 2630 (2005)

12. P. Cristiani, A. Franzetti, and G. Bestetti, Electrochim. Acta, 54(1), 41 (2008).

13. H. H. JyväsjärviJussi and Marko Järvinen, Canadian Journal of Fisheries and Aquatic Sciences, 2014.(2016). 
14. Italian Parliament, "DECRETO LEGISLATIVO 3 aprile 2006, n. 152." Gazzetta Ufficiale, (2006).

15. G. Papaharalabos, J. Greenman, C. Melhuish, C. Santoro, P. Cristiani, B. Li, and I. Ieropoulos, Int. J. Hydrogen Energy, 38(26), 11552 (2013).

16. E. Guerrini, M. Grattieri, A. Faggianelli, P. Cristiani, and S. Trasatti, Bioelectrochemistry, 106, 240 (2015).

17. C. Santoro, K. Artyushkova, S. Babanova, P. Atanassov, I. Ieropoulos, M. Grattieri, P. Cristiani, S. Trasatti, B. Li, and A. J. Schuler, Bioresour. Technol., 163, 54 (2014)

18. M. Daghio, V. Tatangelo, A. Franzetti, I. Gandolfi, M. Papacchini, A. Careghini, E. Sezenna, S. Saponaro, and G. Bestetti, Chemosphere, 130, 34 (2015).

19. R. C. Edgar, Nat. Methods, 10(10), 996 (2013).

20. Q. Wang, G. M. Garrity, J. M. Tiedje, and J. R. Cole, Appl. Environ. Microbiol., 73(16), 5261 (2007)

21. R Core Team, $R$ Foundation for Satistical Computing, Vienna, Austria, (2013).

22. H. Yang, M. Zhou, M. Liu, W. Yang, and T. Gu, Biotechnol. Lett., 37(12), 2357 (2015).

23. I. S. Chang, J. K. Jang, G. C. Gil, M. Kim, H. J. Kim, B. W. Cho, and B. H. Kim, Biosens. Bioelectron., 19(6), 607 (2004).

24. L. Peixoto, B. Min, G. Martins, A. G. Brito, P. Kroff, P. Parpot, I. Angelidaki, and R. Nogueira, Bioelectrochemistry, 81(2), 99 (2011).
25. ] E. Guerrini, M. Grattieri, S. P. Trasatti, and P. Cristiani, International Journal of Hydrogen Energy 39(36), (12), 21837 (2014).

26. P. Cristiani, A. Franzetti, I. Gandolfi, E. Guerrini, and G. Bestetti, Int. Biodeterior. Biodegrad., 84, 211 (2013)

27. P. D. Kiely, J. M. Regan, and B. E. Logan, Curr. Opin. Biotechnol., 22(3), 378 (2011).

28. F. Aulenta, A. Canosa, P. Reale, S. Rossetti, S. Panero, and M. Majone, Biotechnol. Bioeng., 103(1), 85 (2009).

29. A. Sotres, L. Tey, A. Bonmatí, and M. Viñas, Bioelectrochemistry, 111, 70 (2016).

30. M. Daghio, I. Gandolfi, G. Bestetti, A. Franzetti, E. Guerrini, and P. Cristiani, $N$. Biotechnol., 32(1), 79 (2015).

31. M. Daghio, E. Vaiopoulou, S. A. Patil, A. Suàrez-Suàrez, I. M. Head, A. Franzetti, and K. Rabaey, Appl. Environ. Microbiol., 82(1), 297 (2016).

32. P. Roustazadeh Sheikhyousefi, M. Nasr Esfahany, A. Colombo, A. Franzetti, S. P. Trasatti, and P. Cristiani, Applied Energy, in press, (2016).

33. C. Pfeffer, S. Larsen, J. Song, M. Dong, F. Besenbacher, R. L. Meyer, K. U. Kjeldsen, L. Schreiber, Y. A. Gorby, M. Y. El-Naggar, K. M. Leung, A. Schramm, N. Risgaard-Petersen, and L. P. Nielsen, Nature, 491(7423), 218 (2012).

34. M. Wei, F. Harnisch, C. Vogt, J. Ahlheim, T. R. Neu, and H. H. Richnow, RSC Adv., 5(7), 5321 (2015). 